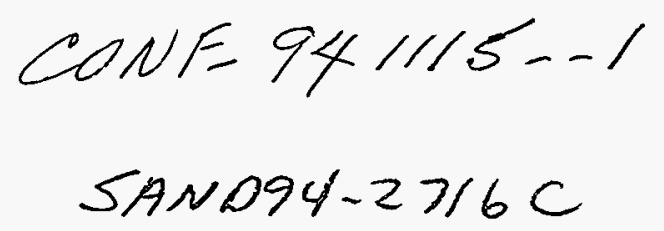

\title{
ACID-SITE CHARACTERIZATION OF WATER-OXIDIZED ALUMINA FILMS BY NEAR-EDGE X-RAY ABSORPTION AND SOFT X-RAY PHOTOEMISSION
}

P.J. O'HAGAN*, R.P. MERRILL*, T.N. RHODIN*, S.W. WORONICK*, N.D. SHINN**, G.L. WOOLERY***, AND A.W. CHESTER***

*Cornell University, Ithaca, NY, 14850

**Sandia National Laboratories, Albuquerque, NM, 87185

***Mobil Research and Development Corporation, Paulsboro, NJ, 08066

\section{ABSTRACT}

Hydroxylated alumina films have been synthesized by water oxidation of single crystal $\mathrm{Al}(110)$ surfaces. Thermal dehydroxylation results in anion vacancies which produce an Al(3s) defect state $3.5 \mathrm{eV}$ below the conduction band edge. A maximum in the defect-DOS occurs for oxides heated to 350 to $400^{\circ} \mathrm{C}$, which is where the materials exhibit maximum Lewis acidity with respect to $\mathrm{C}_{2} \mathrm{H}_{4}$. Adsorbed $\mathrm{C}_{2} \mathrm{H}_{4}$ produces thermally reactive $\mathrm{C}_{2}$ species which interact covalently with the defect-DOS and nonbonding $O(2 p)$ from the top of the valence band. $C(1 s)$ binding energies suggest significant charge transfer which is consistent with a carbenium ion. Ni evaporated onto the surface, however, transfers charge directly to Al species and does not interact with $\mathrm{O}$ atoms at the defect site. The defect-DOS is regenerated when the $\mathrm{C}_{2}$ species decomposes or when Ni migrates thermally through the oxide layer.

\section{INTRODUCTION}

Alumina films are widely used in corrosion inhibition, as dye receptors, as insulators, and as optical coatings. Usually, these films consist of either of amorphous alumina or of one of several "transition" aluminas. They are metastable phases which form depending on the hydrothermal history of the film ${ }^{1}$. Amorphous alumina has primarily tetrahedral coordination while sapphire is octahedrally coordinated. Transition aluminas are characterized by varying ratios of tetrahedral to octahedral coordination. Some phases, $e g \gamma$ and $\eta$, are poorly crystallized and have surface areas of several hundred $\mathrm{m}^{2} / \mathrm{g}$, when they are prepared as bulk powders. These high surface area materials, which are usually synthesized from hydrous gels, are commonly employed as adsorbents, catalysts and catalyst supports. Surfaces of these materials are presumed to be terminated in hydroxyl $(\mathrm{OH})$ groups. Such powders owe much of their rich surface chemistry to the presence of acid sites ${ }^{2}$ which occur when the surface is partially dehydroxylated ${ }^{3}$. Though these reactive surface acids have been characterized by their chemical behavior and by infrared absorptions, little is known about their electronic structure. In this paper we report, for the first time, on the electronic structure of acidic defect sites in planar alumina films and the effects of basic adsorbates and metal deposits on that structure.

The electronic structure of alumina has been investigated intensely for many years. The apparent binding energy for the $\mathrm{Al}(2 \mathrm{p})$ core level shows shifts of a few $\mathrm{eV}$ in $\mathrm{x}$-ray photoemission spectra (XPS) for the different crystallographic forms but these shifts can be accounted for largely by charge transfer effects at the metal/insulator interface ${ }^{6}$ and by small extra-atomic relaxation shifts. ${ }^{7}$ The band gap has been found to be between $8.7 \mathrm{eV}^{8}$ and 9.9 $\mathrm{eV}^{\prime}$. From a variety of measurements the valence band edge can be located ca $80 \mathrm{eV}$ above the $\mathrm{Al}(2 \mathrm{p})$ core level. An exciton $\mathrm{ca} 1 \mathrm{eV}$ below the conduction band has also been observed in $\alpha-$ alumina. ${ }^{2-10}$

It has been suggested that surface acidity in aluminas results primarily from coordinatively unsaturated aluminum sites. Since some, if not the majority, of these acid sites function as Lewis acids, $i$ e electron acceptors, it is possible that, electronically, they would produce empty 


\section{DISCLAIMER}

\section{Portions of this document may be illegible in electronic image products. Images are produced from the best available original document.}


defect states in the upper portion of the band gap. Such states would appear as pre-edge features in the soft $x$-ray absorption spectrum.

In this work we report on studies of soft x-ray photoemission (XPS) and absorption (XAS) on thin films, 20 to $50 \AA$ thick, of alumina grown by water oxidation of single crystal Al(110). The films were then heated to various temperatures up to $500^{\circ} \mathrm{C}$. Water oxidation was used to maximize the incorporation of $\mathrm{OH}$ groups. The XPS and XAS measurements were made at NSLS on the U16B beamline, which is equipped with an extended range grasshopper monochrometer (ERG). The use of synchrotron radiation in this work makes it possible to complete the equivalent of ultraviolet photoelectron spectroscopy (UPS), XPS, and XAS on a single sample with a carefully controlled preparation. All of the photoemission spectroscopy can be carried out with photoelectrons which have the same range of kinetic energies. This means that they sample the same portion of the material. The ERG monochrometer has excellent transmission at the energies required for $\mathrm{Al}(2 \mathrm{p}), \mathrm{C}(1 \mathrm{~s})$, and $\mathrm{O}(1 \mathrm{~s})$ spectroscopies. The use of thin films gives an internal calibration of all binding energies by referencing them with respect to the known binding energy Al-metal.

\section{RESULTS AND DISCUSSION}

All the films were prepared by oxidation of $\mathrm{Al}(110)$ surfaces with water at room temperature and then rapidly heated (flashed) to a selected temperature $\left(\leq 500^{\circ} \mathrm{C}\right)$ and quenched. XPS and XAS measurements were then taken at room temperature. The XPS data were acquired with a cylindrical mirror analyzer and the XAS were obtained using total electron yield.

The results of the XPS measurements have been described in detail elsewhere ${ }^{11}$ but will be summarized briefly here. As the treatment temperature increased, the $\mathrm{OH}$-content of the films decreased monotonically and the degree of crystallinity increased monotonically. Adsorption of ethylene, a weak Lewis base (electron donor), produced a binding energy shift of $+2.8 \mathrm{eV}$ in the $\mathrm{O}(1 \mathrm{~s})$ core level for a portion of the oxygen species but no measurable shift in the $\mathrm{Al}(2 \mathrm{p})$ level. The intensity of the shifted oxygen species passes through a maximum for materials flashed to temperatures between 350 and $400^{\circ} \mathrm{C}$. The valence band spectra show that whatever molecular fragments are present still retain the $C_{2}$ structure of ethylene. The ethylene-derived valence band states are consistent with the presence of a ${ }^{+} \mathrm{C}_{2} \mathrm{H}_{5}$, a carbenium ion. Carbenium ions are known to be a very reactive intermediates ${ }^{2}$. This expectation was corroborated when the surface was warmed rapidly from $120 \mathrm{~K}$ to $210 \mathrm{~K}$ and then quenched. Such treatments removed all traces of the $C_{2}$ species but resulted in little change in the total amount of carbon on the surface.

\section{Alumina Films}

The absorption spectra for films produced at room temperature and subsequently flashed to higher temperatures, up to $500^{\circ} \mathrm{C}$, are shown in figure 1 for absorption about the $\mathrm{Al}(2 \mathrm{p})$ edge. The intensities of the total electron yields are plotted as a function of the energy of the incident photon. In all of the spectra, there is a small but distinctive feature near $72.5 \mathrm{eV}$ which results from the aluminum metal substrate, $i e$ the $2 p$ edge. There is some incorporation of metallic aluminum in nearly all UHV-grown oxides, either as a result of a nonplanar metal/oxide interface or as small metal crystallites within the oxide matrix. ${ }^{12,13}$ The Fermi edge of Al-metal is also evident in the valence band spectra of these materials. "The splitting due to spin-orbit coupling is observed in the metal edges shown in figure 1. XPS binding energies for

Al-metal are 72.5 and $72.9 \mathrm{eV}$ for the two spin states, which coincides with the splitting shown at the metal edges in figure $1 .^{14}$

The rest of the features are attributed to electron transitions in the oxide. Peaks at 76.5, 80.0 and $83.4 \mathrm{eV}$ are present in all of the films. An additional feature between 78 and $79 \mathrm{eV}$ is seen in the oxides flashed to temperatures above $400{ }^{\circ} \mathrm{C}$ but absent those treated at lower temperatures. The feature at $80.0 \mathrm{eV}$ is the main absorption edge and coincides with excitation 
from $\mathrm{Al}(2 \mathrm{p})$ into the lower part of the conduction band. Subtracting 71.3 , the measured $\mathrm{Al}(2 \mathrm{p})$ binding energy with respect to the valence band edge gives $8.7 \mathrm{eV}$ for the band gap which is equal to that reported from optical reflectance measurements on sapphire. ${ }^{9}$ Following Balzarotti et al $^{\text {s }}$ the main edge, $80.0 \mathrm{eV}$, is assigned to the $\mathrm{Al}(2 \mathrm{p}) \rightarrow \mathrm{Al}(3 \mathrm{~s})$ transition and the 83.4 peak to $\mathrm{Al}(2 \mathrm{p}) \rightarrow \mathrm{Al}(3 \mathrm{~d})$. The remaining features in figure 3 have final state energies that lie within the gap and their assignments are more tentative. The $78.8 \mathrm{eV}$ feature in the oxides flashed to above $400^{\circ} \mathrm{C}$ is attributed to an exciton by analogy to that found in $\alpha$ alumina. ${ }^{2-10}$ The exciton is not present in the room temperature oxide, first appears at $78.3 \mathrm{eV}$ in the material flashed to $425^{\circ} \mathrm{C}$, and then grows in intensity with temperature until it overshadows the $\mathrm{Al}(2 \mathrm{p}) \rightarrow \mathrm{Al}(3 \mathrm{~s})$ peak.

The more prominent and pervasive feature within the gap is the one at $76.5 \mathrm{eV}$, which is 3.5 $\mathrm{eV}$ below the conduction band edge. This energy is three times the binding energy of the exciton observed for $\alpha$-alumina and has a density of states (DOS) that is distinct with respect to the observed exciton, which has a binding energy similar to that of the exciton in $\alpha$-alumina. We therefore assign this feature to a geometric defect. At these treatment temperatures one would expect to find small crystallites of $\gamma$-alumina in a matrix of amorphous material. ${ }^{11}$ Such a material would have myriads of defects some of which could be expected to produce states within the gap. The intensity of this defect state passes through a maximum for materials flashed to temperatures of 350 to $400^{\circ} \mathrm{C}$, which is the temperature range at which the materials show their maximum Lewis acidity with respect to ethylene. ${ }^{11}$

Tight-binding band structure calculations ${ }^{16}$ and cluster calculations ${ }^{17}$ on $\alpha$-alumina all show defect states within the band gap either for Al-terminated surfaces or for O-terminated surfaces with anion vacancies. All the calculations exhibit an $\mathrm{Al}\left(3 \mathrm{~s}, \mathrm{p}_{\mathrm{z}}\right)$ DOS which has dropped below the bottom of the conduction band and a destabilization of O(2p)-DOS near the top of the valence band. A defect state $4 \mathrm{eV}$ below the conduction band has been identified in electron loss spectroscopy (ELS) on the (1012) surface. ${ }^{18}$ ELS spectra from reconstructed and ion-bombarded (0001) surfaces also exhibit empty states within the band gap. ${ }^{19}$ While none of these electronic structure calculations can be applied directly to transition aluminas, the defect-DOS they reveal within the band gap and the experimental observations of defect-DOS add credence to our assignment of the $76.5 \mathrm{eV}$ peak to a defect state. The dipole selection rule implies that the defect-DOS in figure 1 has primarily s-character and can therefore be attributed to $\mathrm{Al}(3 \mathrm{~s})$. XAS spectra at the oxygen edge show no pre-edge features for any of the films studied. In contrast to the calculations on $\alpha$-alumina, this indicates little $\mathrm{Al}(3 \mathrm{p})$ contribution to the defect-DOS. No electronic structure calculations have been reported for geometries which represent transition aluminas and no defect states have been previously identified experimentally in the transition aluminas.

\section{Adsorbates; Ethylene and Nickel}

Adsorption and/or deposition of Lewis bases (electron donors) would be expected to produce strong interactions with these defect states. Figure 2 shows the effects of surface species resulting from ethylene adsorption. The defect-DOS is shown for a film flashed to $350^{\circ} \mathrm{C}$, which, as mentioned earlier, produces a maximum in the defect-DOS. Spectra are shown prior to ethylene adsorption, after adsorption at $120 \mathrm{~K}$, and after warming to $210 \mathrm{~K}$. Recall that surfaces flashed to $210 \mathrm{~K}$ result in decomposition of $\mathrm{C}_{2}$ species. When ethylene is adsorbed, the intensity of the defect-DOS decreases and the intensity of the DOS at the bottom of the conduction band increases. This is accompanied by a sharp decrease in the DOS at the valence band edge $e^{11}$, which suggests stabilization of the $O(2 p)$ states which reside there. Further evidence for the involvement of oxygen in the bonding comes from the increase in the apparent binding energy of $\mathrm{O}(1 \mathrm{~s})$. This shift is similar to that found for $\mathrm{OH}$-groups and probably results, in both cases, from a final state effect rather than a significant charge transfer from oxygen to hydrogen. It does suggest, however, a strong interaction between oxygen and the hydrogen in the C-H groups of the $\mathrm{C}_{2}$ species. There is no significant shift in the Al(2p) binding energy but the $\mathrm{C}(1 \mathrm{~s})$ core levels show a large shift, $c a+4 \mathrm{eV}$, which is consistent with a carbenium ion like ${ }^{+} \mathrm{C}_{2} \mathrm{H}_{\text {s }}$. 
Transition metals can be either electron donors or acceptors. Metals late in the period, eg $\mathrm{Ni}, \mathrm{Pd}$, and Pt should be stronger Lewis bases (electron donors) than the early members. With this in mind, Ni was deposited at $90 \mathrm{~K}$ on alumina films prepared to have maximum Lewis acidity. The total-yield-XAS is shown in figure 3 for deposition of 3 equivalent monolayers of nickel. Also present is a spectrum from the oxide layer prior to Ni deposition. When nickel is deposited, the Ni(3p) edge appears prominently in the XAS and all of the oxide features are attenuated, but the ratio of the $\mathrm{Al}(3 \mathrm{~s})$ defect to the $\mathrm{Al}^{\circ}$ edge decreases by a factor of 2 . As the treatment temperature increases and the Ni eventually migrates through the oxide layer into the bulk, ${ }^{20}$ the intensity of the defect-state is regenerated and that of the nickel edge decreases. Like ethylene, Ni interacts strongly with the acid site. Unlike ethylene, however, there is no appreciable gain in the intensity of the DOS near the bottom of the conduction band. This probably indicates that the interaction with Ni broadens and/or destabilizes the $\mathrm{Al}(3 \mathrm{~s})$ much more than the ethylene interaction does. There are other important differences in the Ni-interaction compared to ethylene. Nickel produces no shifts in the $\mathrm{O}(1 \mathrm{~s})$ binding energy but there is a shift of $+0.8 \mathrm{eV}$ in $\mathrm{Ni}(3 \mathrm{p})$ indicating significant charge transfer to the acid site as expected. This results in a shift of $-1.3 \mathrm{eV}$ for the $\mathrm{Al}(2 \mathrm{p})$ level. Charge transfer to the oxide should decrease the amount of band bending which would increase the apparent binding energy; thus the $-1.3 \mathrm{eV}$ value represents the net difference between these two effects.

Using synchrotron radiation for this work has provided information about these acidic defects in alumina in unprecedented detail. We have been able to identify their energy unambiguously and their orbital symmetry. We have shown how these specific defects interact electronically in strong chemical reactions with a hydrocarbon molecule and a transition metal, identifying details about the nature of the bonding modes. This probably represents the first characterization of the electronic structure of solid acids in such detail.

\section{Conclusions}

Both ethylene and nickel interact strongly with acidic $\mathrm{Al}(3 \mathrm{~s})$ defect-states which occur as a result of dehydroxylation of the surface. While Ni interacts primarily with $\mathrm{Al}(3 \mathrm{~s})$-states and transfers charge to the aluminum center, ethylene interacts strongly also with the oxygen species and has primarily covalent interactions with $\mathrm{Al}(3 \mathrm{~s})$. The defect sites are regenerated when the ethylene-derived $\mathrm{C}_{2}$-species decompose or when $\mathrm{Ni}$ migrates through the oxide into the bulk. These measurements represent the first direct characterization of chemically active acid sites on alumina.

\section{ACKNOWLEDGEMENT}

Primary support was provided by the Mobil Research and Development Corporation. Additional support came from the Cornell Materials Science Center under NSF Grant DMR16616-AO2 and from DOE-BES (Material Sciences) under Contract ACO4-94AL85000 with Sandia National Laboratories. Measurements were conducted at the National Synchrotron Light Source, Brookhaven National Laboratories, Upton, NY 11973, which is supported by the Office of Basic Energy Sciences, United States Department of Energy, under Contract DEACO2-76CH0O016.

\section{LITERATURE CITATIONS}

1. D.L. Cocke, E.D. Johnson, and R.P. Merrill, Catal. Rev.-Sci. Eng. 26163 (1984)

2. H. Pines, The Chemistry of Catalytic Hydrocarbon Conversions, (Academic Press, 1981) Chapter 1 
3. H. Knözinger, in Acid-Base Catalysis, edited by K. Tanabe, H. Hatori, T. Yamagochi, and T. Tanoka, (VCHS Press, Kodancha, 1988)

4. See for example; H. Pines, op cite, p 13

5. J. Kijenski and A. Baiker, Catal. Today 5, 1 (1989); H. Knözinger, Op Cite p147; A. Aroux and A. Gervasini, J. Phys. Chem 94, 6371 (1990)

6. C-C. Kao, PhD Thesis, Cornell University (1988)

7. C-C. Kao and R.P. Merrill, J. Phys. Chem. Solids 52909 (1991)

8. A. Balzarotti, F. Antonangeli, R. Girlanda, and G. Martino, Solid State Comm. 44275 (1982)

9. W.L O'Brien, J. Jia, Q-Y. Dong, T.A. Callcutt, J-E. Rubensson, D.L.Mueller, and D.L. Ederer, Phys. Rev. B 441013 (1991)

10. W.L. O'Brien, J. Jia, Q-Y. Dong, T.A. Callcott, J-E. Rubensson, D.L. Mueller, N.D. Shinn, and S.C. Woronick, Phys Rev. B 4413277 (1991)

11. T.N. Rhodin, R.P. Merrill, P.J. O'Hagan, S.C. Woronick, N.D. Shinn, G.L. Woolery, and A.W. Chester, J. Phys. Chem. 982433 (1994)

12. E.D. Johnson $\mathrm{PhD}$ Thesis, Cornell University (1988)

13. B.G. Frederick, G. Apai, and T.N. Rhodin J. Am. Chem. Soc. 1094797 (1987)

14. D. Vaughn, editor X-Ray Data Booklet (Center for X-Ray Optics, LBL U. of Calif., Berkeley, 1986)

15. A. Balzarotti, F. Antonangeli, R. Girlanda, and G. Martino Phys. Rev. B 295903 (1984)

16. S. Ciraci and I Batra, Phys. Rev. B 28982 (1983);P. Alemany, R. Boorse, J. Burlitch, and R. Hoffmann, J. Chem. Phys. 978464 (1993)

17. J. Guo, D. Ellis, and D. Lam, Phys. Rev. B 4513647 (1992)

18. W.J. Gignac, R.S. Williams, and S.P. Kowalcyk, Phys. Rev. B 321237 (1985)

19. M. Gautier, J.P. Duraud, L. Pham Van, M.J. Guittet, Surf. Sci. 250, 71 (1991)

20. P.J. O'Hagan, PhD Thesis, Cornell University (1995)

\section{DISCLAIMER}

This report was prepared as an account of work sponsored by an agency of the United States Government. Neither the United States Government nor any agency thereof, nor any of their employees, makes any warranty, express or implied, or assumes any legal liability or responsibility for the accuracy, completeness, or usefulness of any information, apparatus, product, or bility for the accuracy, completeness, or use would not infringe privately owned rights. Reference herein to any specific commercial product, process, or service by trade name, trademark, manufacturer, or otherwise does not necessarily constitute or imply its endorsement, recommendation, or favoring by the United States Government or any agency thereof. The views and opinions of authors expressed herein do not necessarily state or reflect those of the United States Government or any agency thereof. 


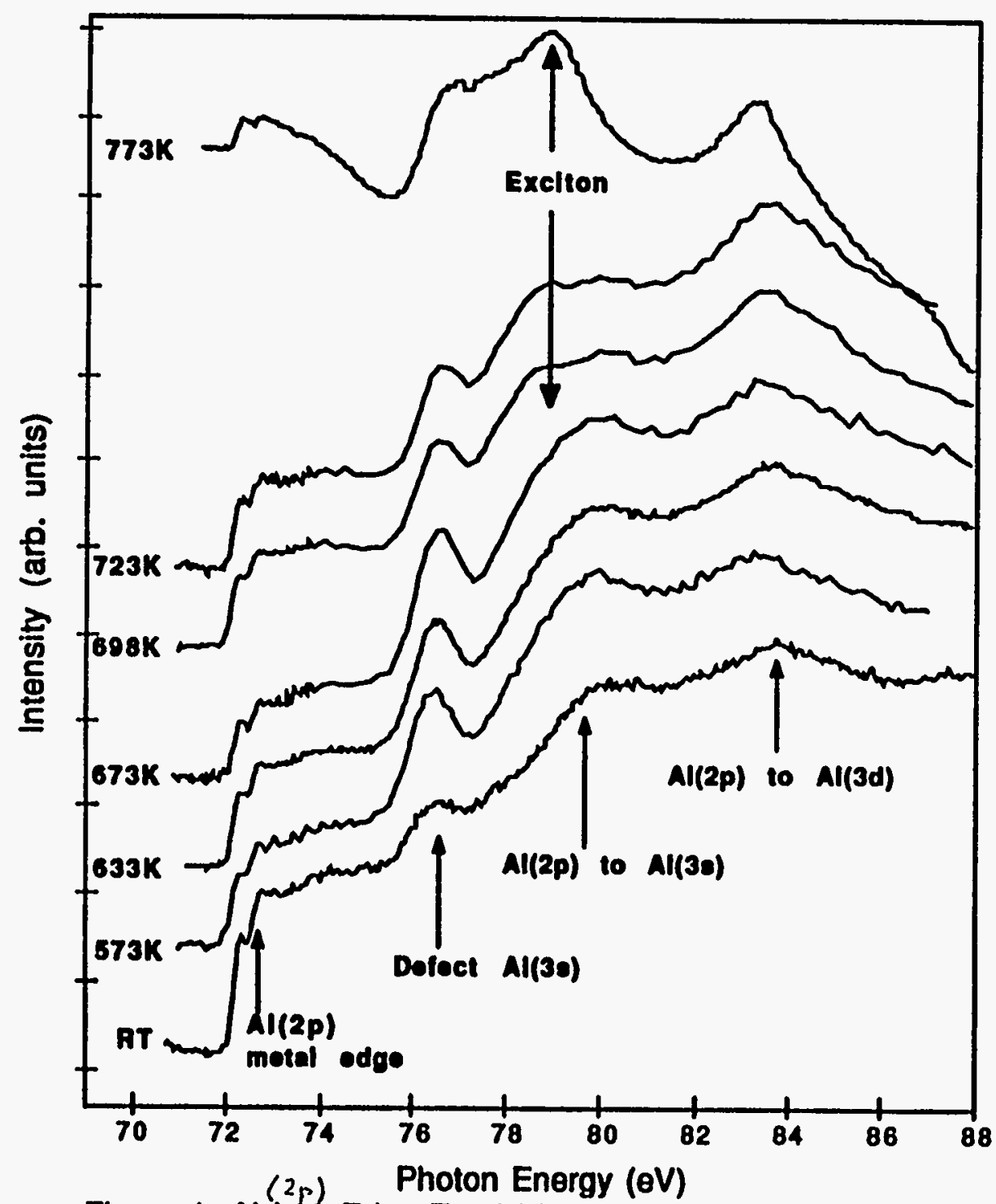

Figure 1: Al 123 Edge Total Electron Yield Spectra for Heat Treated Alumina Films.

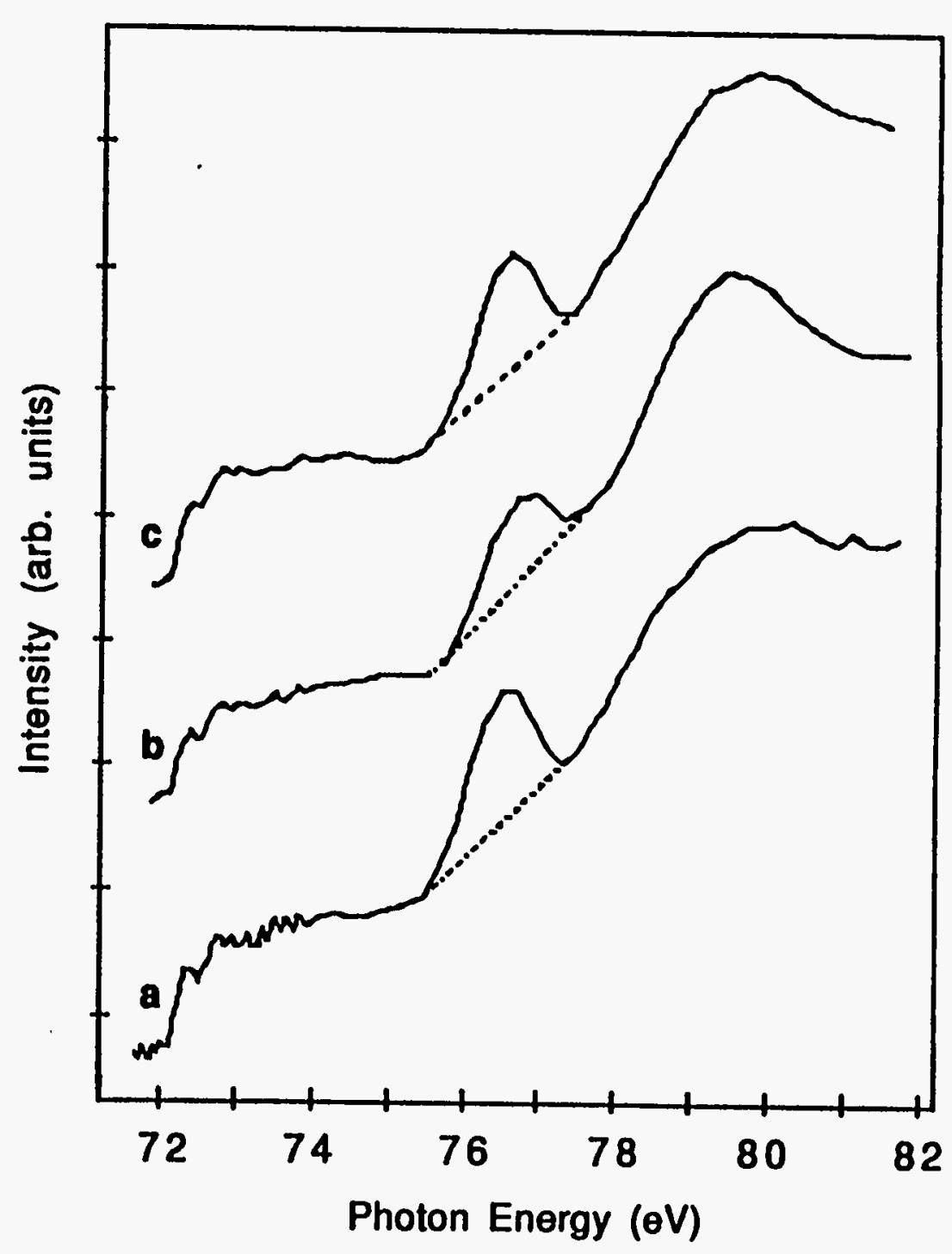

Figure 2: X-ray Absorption Spectra for a) 673K Heat Treated Film. b) 673K Film after Ethylene Exposure, (c) After Warming the Ethylene Dosed Film to 210K. 


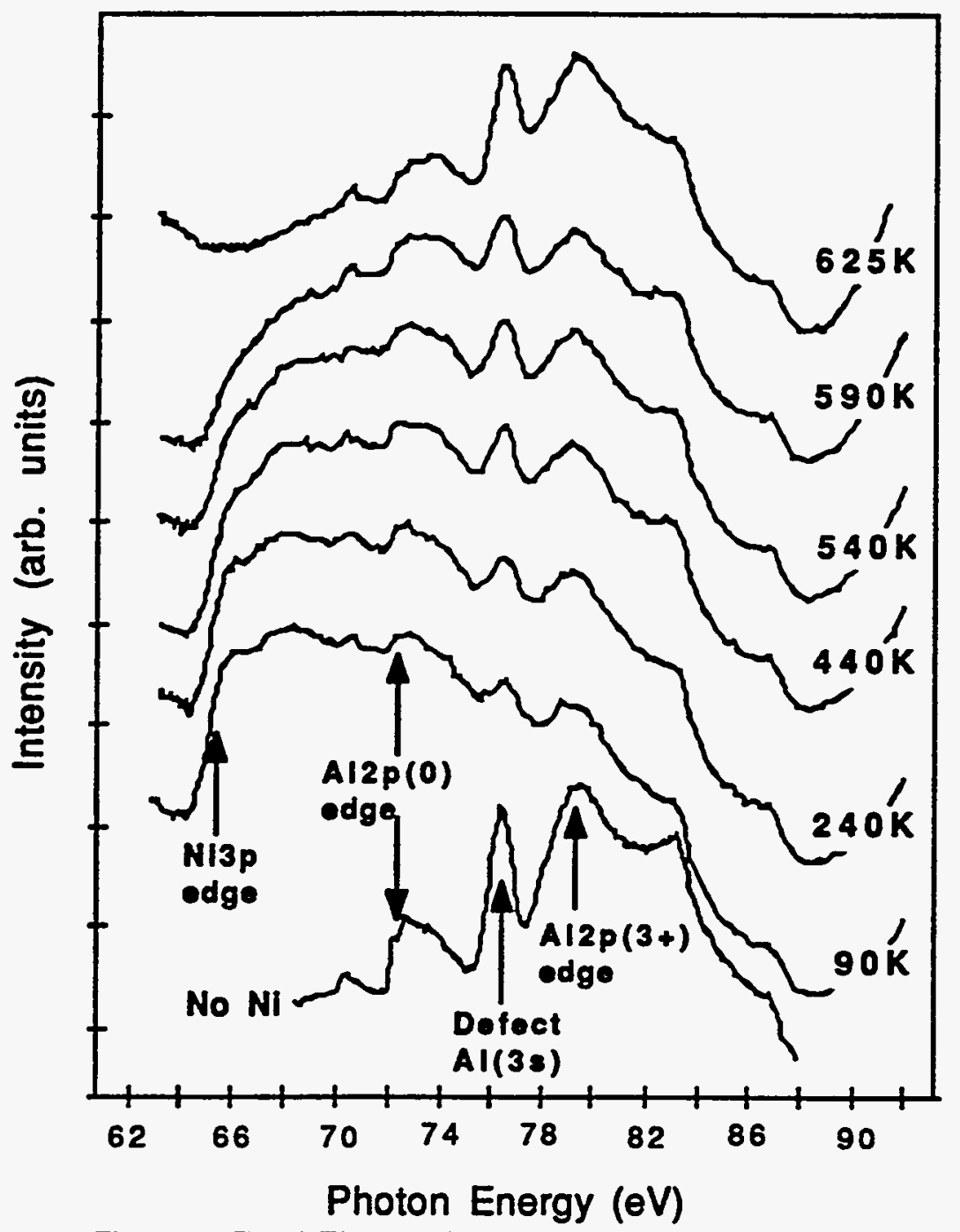

Figure 3: Total Electron Yield Near Edge Spectra for a $3 \mathrm{ML}$ Nickel Film 